\title{
LOW COST INVERTER USING H-BRIDGE TO CONVERT SOLAR ENERGY
}

\author{
Meghashree G.N ${ }^{1}$, Meghana.S ${ }^{2}$, Charishma.C ${ }^{3}$, A.Swetha ${ }^{4}$ \\ ${ }^{1}$ B.E (Electronics and Communication), K.S.I.T, Bangalore \\ ${ }^{2}$ B.E (Electronics and Communication), K.S.I.T, Bangalore \\ ${ }^{3}$ B.E (Electronics and Communication), K.S.I.T, Bangalore \\ ${ }^{4}$ B.E (Electronics and Communication), K.S.I.T, Bangalore \\ ${ }^{1}$ meghashreegn2011@gmail.com, ${ }^{3}$ charishma2094@gmail.com
}

\begin{abstract}
Nowadays the need for the electricity is increased in a great manner, so it is necessary to produce electricity in a large amount using renewable sources. One of the most abundant renewable sources of energy is solar energy. This paper aims in designing the low cost PWM inverter using solar energy which produces a sine wave and is controlled using a microcontroller. The generated sinusoidal wave will be of very less harmonics. The technique on which inverter works is mainly based on the pulse width modulation technique which is generated and controlled by microcontroller. The obtained inverter is tested with different AC loads and is primarily concentrated on low power consuming electronic devices such as routers, chargers, bulbs etc. The suggested model of the inverter is of low cost and it's a feasible design. The design is simulated using Proteus software to get the desired output results which is verified practically.
\end{abstract}

Keywords: ATMEGA832 Microcontroller, Sinusoidal Pulse Width Modulation, Voltage Sensors, H-Bridge Inverter. ****

\section{INTRODUCTION}

which effectively transforms a low DC voltage to a high voltage AC source compatible with the power supplied to an electrical outlet $(120 \mathrm{Vrms}, 50 \mathrm{~Hz})$.Most of the Electronic devices run on AC supply, batteries and other few forms of power generations produces a DC voltage sources, hence it is essential to convert the DC voltage into a voltage that devices can use.

A low voltage $\mathrm{DC}$ power is inverted into a high voltage $\mathrm{AC}$ power in two methods. In first method the DC voltage is stepped up by using a boost converter to a very high voltage. This high voltage DC power is then converted into an AC source using pulse width modulation technique. Second method includes initially converting the DC source into AC source at low level voltages and then stepping up the AC source using a transformer. A transformer though is less efficient and it adds to the overall size of the system and cost of a system. This project deals on the work of a foregoing group that was given the similar work of designing a $\mathrm{DC}$ to $\mathrm{AC}$ inverter.

The preceding batch took an analog approach in the execution of their system. While there are few advantages to this, it limits the malleability of the system in that it can only be used for a particular purpose and if it is needed for the design change, the process is very difficult and is potentially
The priority of this paper is to design a DC to AC inverter labor comprehensive. In our project, we minutiae how the PWM inverter's are implemented using H-bridge to convert low DC to high AC in effective and efficient manner.

\section{PROBLEM STATEMENT}

In these days, necessity of the electricity is increasing but non renewable energy sources are getting exhausted which is a very serious problem to be considered .Hence the use of renewable energy must be considered and preserve the non renewable energy sources. The renewable solar energy absorbed will not be suitable for the power devices. Hence the inverters will be required to convert DC to AC energy.

Inverters are of different types where conversion of energy is obtained. Although there are many inverters there efficiency in delivering the power is less. Hence to overcome this problem we are using $\mathrm{H}$-bridge inverter where efficiency is increased and cost effective [1].

\section{INVERTER CONCEPT}

As the renewable energy necessity has been extended, the energy which is obtained from the renewable energy sources will be in the DC form which is not suitable for the general power devices applications .Hence there is a requirement of the inverter in a greater extends. 


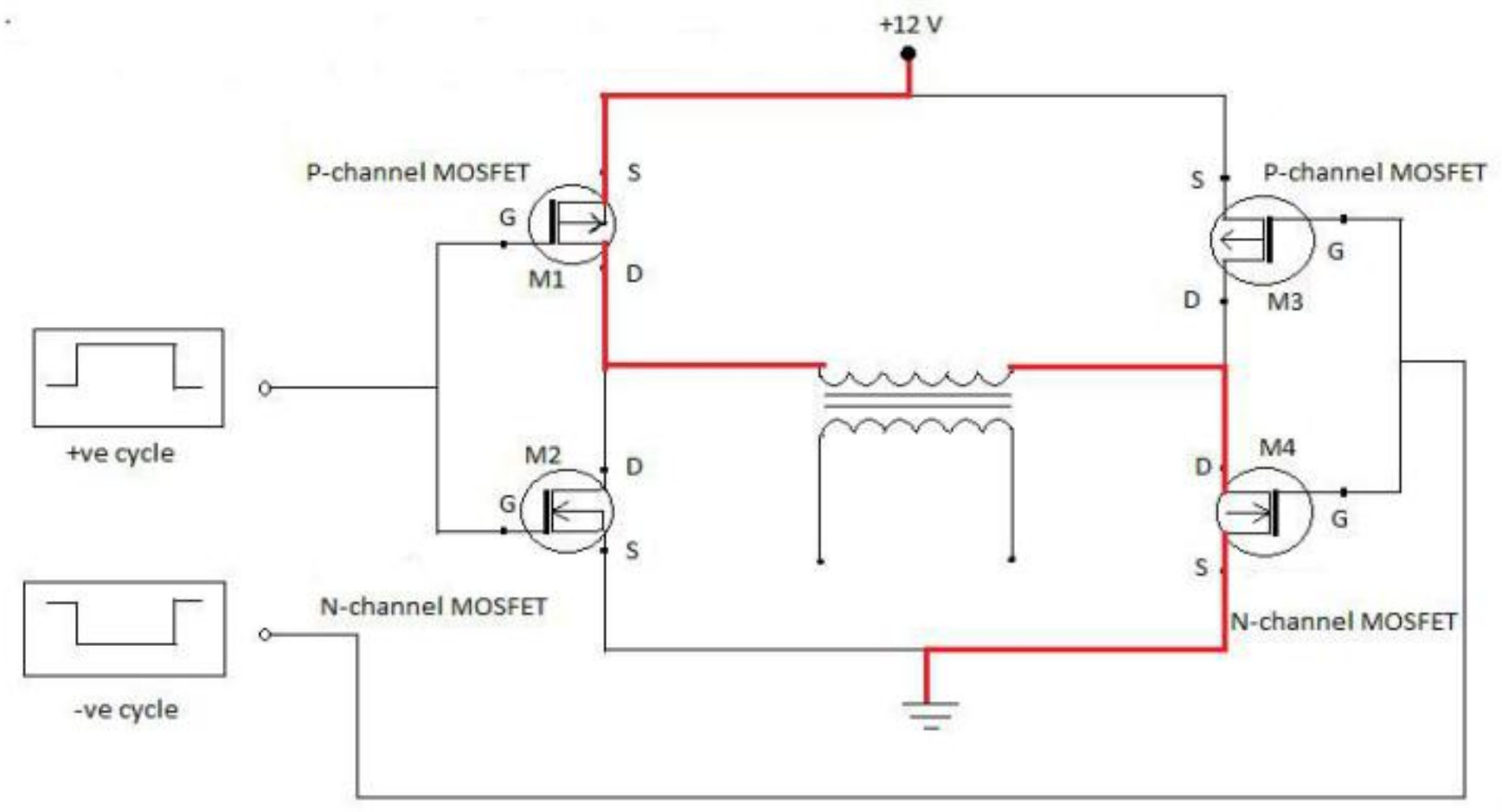

Fig1. H-bridge inverter circuit.

Inverters are simple circuits which will convert the DC form into AC which is very essential. There are many types of inverters like BJT, MOSFET etc. The inverter which we use in the proposed system is an H-bridge inverter as shown in Fig1. is very efficient when compare to other inverter circuits.

\section{PROPOSED DESIGN}

An array of Photovoltaic cells are designed to absorb solar energy. In the present considered design, initially the solar energy is stored in a battery as $12 \mathrm{~V} \mathrm{DC}$. For powering the electronic devices conversion from $12 \mathrm{~V}$ to $210 \mathrm{~V}$ AC is needed hence DC to AC converter with PWM strategy is implemented between the solar panel and the load. The sine wave PWM inverter converts $12 \mathrm{~V}$ DC to $210 \mathrm{~V}$ AC. The main advantage being high efficiency and low energy losses. In addition, a step up transformer which boosts up $12 \mathrm{~V}$ to $210 \mathrm{~V}$ AC is also used. This set up can be used for residential uses. [4].

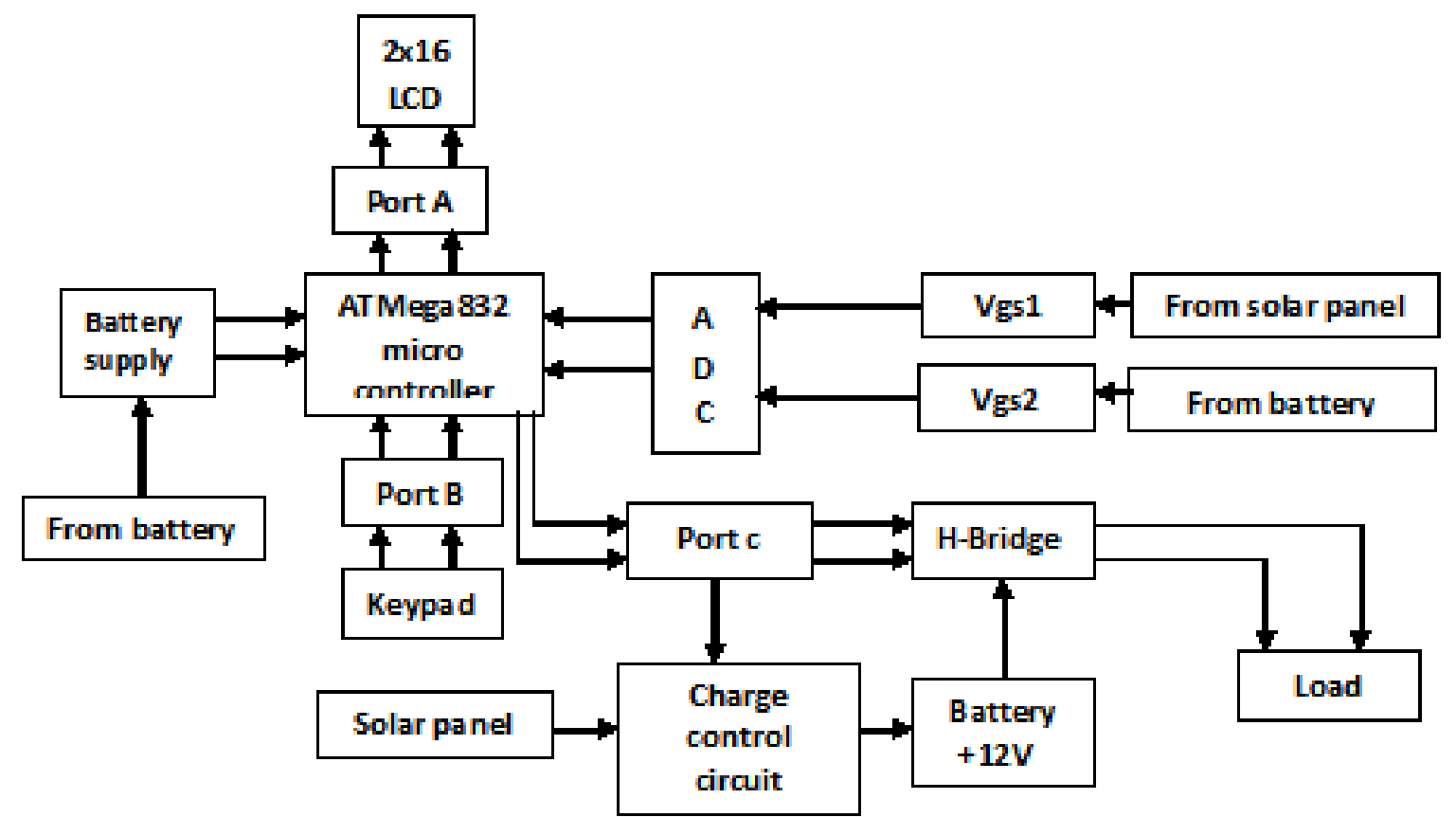

Fig 2. Proposed Block diagram 


\begin{tabular}{|c|c|c|c|c|}
\hline$(\mathrm{XCK} / \mathrm{T} 0)$ PBO $\square$ & 1 & 40 & $\square$ PAO & $(\mathrm{ADC} 0)$ \\
\hline (T1) PB1 ᄃ & 2 & 39 & $\ominus$ PA1 & (ADC1) \\
\hline (INT2/AIN0) PB2 ᄃ & 3 & 38 & $\boxminus$ PA2 & $(A D C 2)$ \\
\hline (OC0/AIN1) PB3 ᄃ & 4 & 37 & $\boxminus$ PA3 & (ADC3) \\
\hline$(\overline{\mathrm{SS}}) \mathrm{PB} 4 \square$ & 5 & 36 & $\square$ PA4 & (ADC4) \\
\hline (MOSI) PB5 $\square$ & 6 & 35 & $\square$ PA5 & (ADC5) \\
\hline (MISO) PB6 $\square$ & 7 & 34 & $\sqsupseteq$ PA6 & $(\mathrm{ADC6})$ \\
\hline (SCK) PB7 $\square$ & 8 & 33 & $\sqsupseteq$ PA7 & (ADC7) \\
\hline$\overline{\mathrm{RESET}}$ & 9 & 32 & $\sqsupseteq$ AREF & \\
\hline VCC $\square$ & 10 & 31 & $\sqsupseteq$ GND & \\
\hline GND ᄃ & 11 & 30 & $\boxminus \operatorname{AVCC}$ & \\
\hline XTAL2 ᄃ & 12 & 29 & $\boxminus$ PC7 & (TOSC2) \\
\hline XTAL1 ᄃ & 13 & 28 & $\boxminus$ PC6 & (TOSC1) \\
\hline (RXD) PD0 $\square$ & 14 & 27 & $\boxminus$ PC5 & (TDI) \\
\hline (TXD) PD1 $\square$ & 15 & 26 & $\square$ PC4 & $(\mathrm{TDO})$ \\
\hline (INT0) PD2 $\square$ & 16 & 25 & $\square$ PC3 & (TMS) \\
\hline (INT1) PD3 $\square$ & 17 & 24 & $\square \mathrm{PC} 2$ & (TCK) \\
\hline (OC1B) PD4 $\square$ & 18 & 23 & $\square$ PC1 & (SDA) \\
\hline (OC1A) PD5 $\square$ & 19 & 22 & $\square \mathrm{PCO}$ & (SCL) \\
\hline (ICP1) PD6 $\square$ & 20 & 21 & $\square$ PD7 & $(\mathrm{OC} 2)$ \\
\hline
\end{tabular}

Fig 3. Pin diagram of ATMEGA83

The overall system is controlled by the microcontroller ATMEGA832 which is one of the advanced microcontrollers. The Fig3. Pin diagrams show an overview of the ATMEGA832 microcontroller.

An H-bridge is a circuit which enables a voltage to be put across a load in any direction. It is of four switches, commonly MOSFETs, and load configuration is in the shape of an ' $\mathrm{H}$ '. Because of this shape controlling which switches are closed at any given moment, the voltage across the load can be either positive, negative, or zero.

\section{METHODOLOGY}

Fig 2.shows the block diagram of the proposed system. The main aim is to provide an output voltage of $220 \mathrm{~V}$ AC of frequency $50 \mathrm{HZ}$ from an input of low DC input voltage. The main source of energy is obtained by the one of the renewable energy sources that is solar energy. This solar energy is observed by the solar panels which converts the solar energy into electrical energy and this energy is then stored in the battery. The transforming of the charges between the solar panel and the battery is controlled by the relay circuit which acts as a switch which disconnects the connection between solar panel and the battery. The stored energy in the battery is given to the $\mathrm{H}$-Bridge inverter where the stored DC energy is converted to the AC voltage and this $\mathrm{AC}$ voltage is stepped up using a step up transformer where the very low DC voltage is boosted up to the 220VAC voltage which is used for running the electronic devices like bulb, chargers etc .The same stored energy from battery is used to control the overall system in addition with the supplying AC voltage to the household applications.

The amount of energy coming from the solar panel is measured by the voltage sensors and the energy stored in the battery is also measured by another voltage sensors and this is displayed in the LCD Display.

\section{ALGORITHM DESIGNED}

The algorithm in the Fig4.contains the following steps:

1. Initially all the ports of the microcontroller is initiated

2. Then setting up the look up table of the sine wave

3. For the positive half cycle calculate the PWM value.

4. If variable value is less than 9 then go to calculating PWM for negative half cycle else go to calculate PWM positive value.

5. Setting up the delay for LCD display and for timers in ATMEGA832.

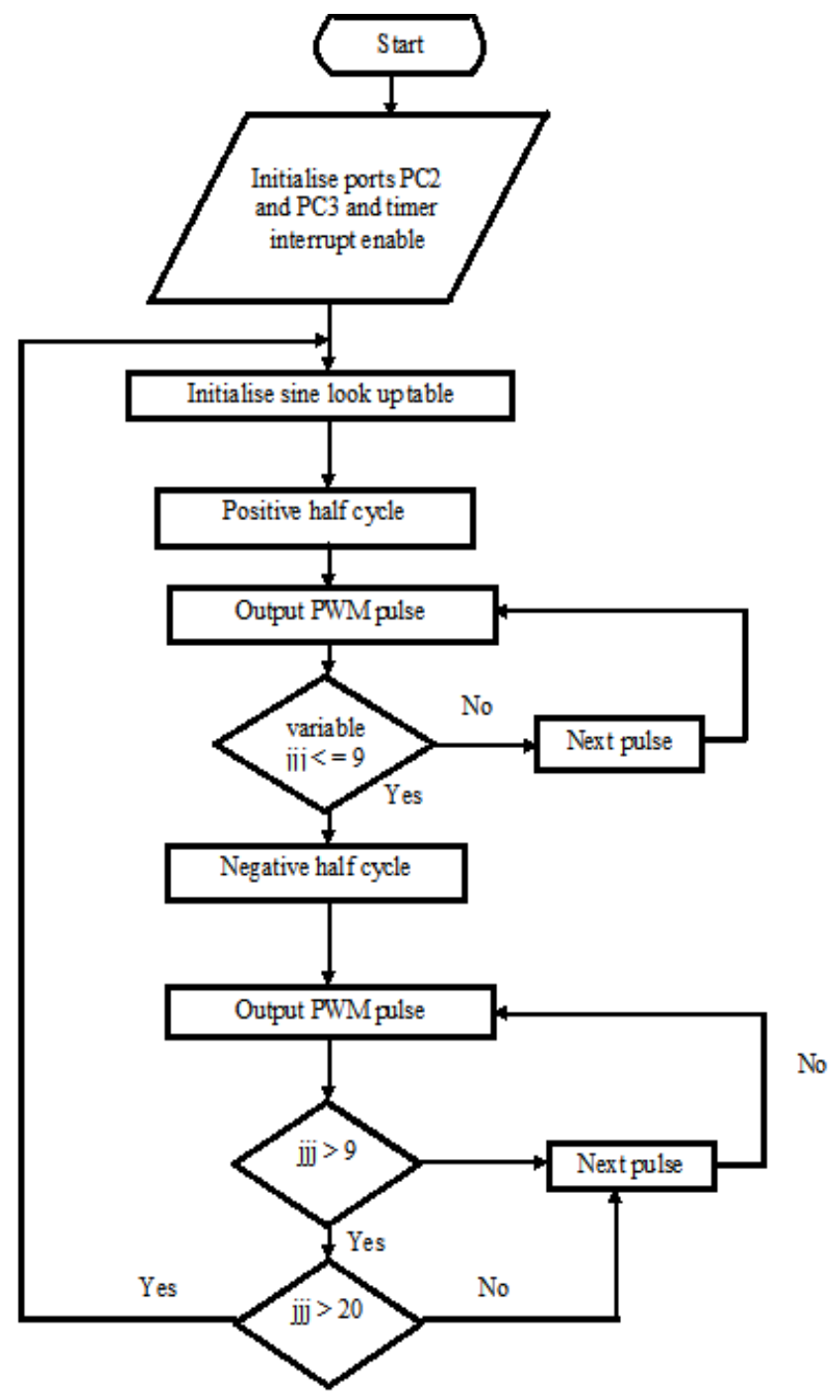

Fig 4.Flow chart of the solar inverter

\section{SIMULATION RESULTS}

The result of generation of the PWM is given in fig5. The system is simulated using the Proteus software and the PWM pulses are generated by enabling the timers of the microcontroller ATMEGA832. 


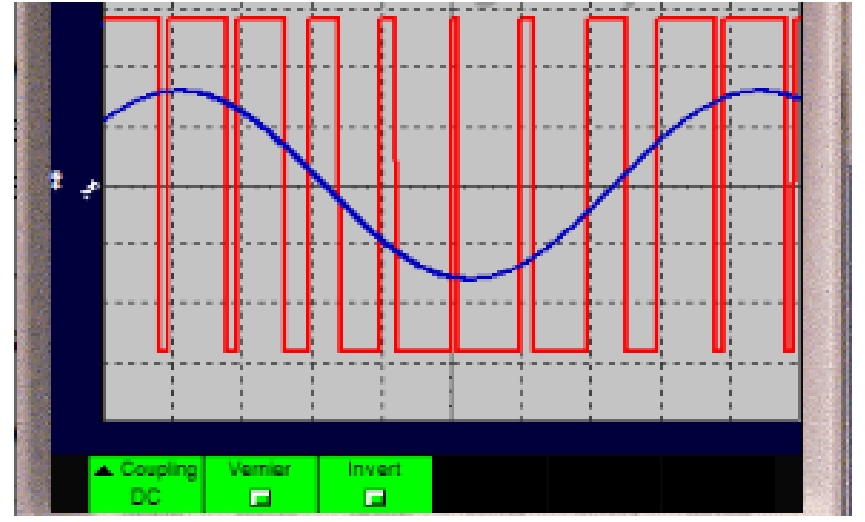

Fig 5.Generation of the sinusoidal PWM pulses

\section{RESULTS}

Fig6.shows overall system solar inverter which gives the output of gives an output of $210 \mathrm{~V} \mathrm{AC}$ with $30 \mathrm{~W}$ power. By this we can run most of the home appliances which we use in our day to day life where maximum renewable solar power is utilized.

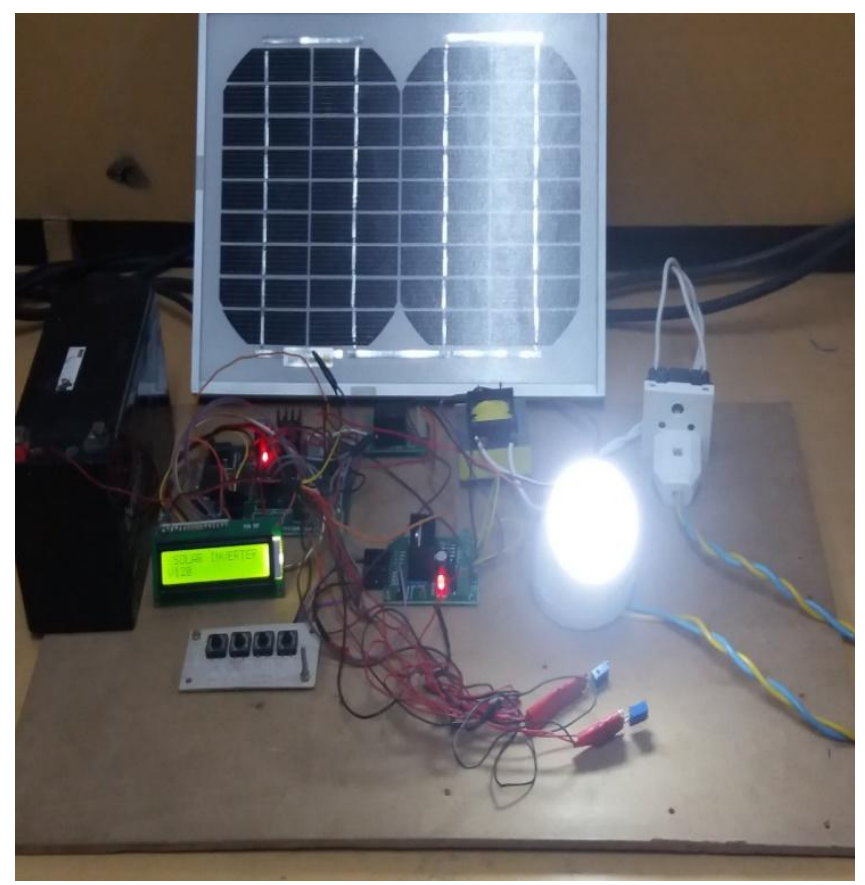

Fig 6.Hardware realization of the proposed project

\section{CONCLUSION}

The main goal of our project is to design and implement a low cost PWM inverter using H-bridge converter, which is more efficient and consumes less power compare to BJT and other converters. Here we have achieved to convert $12 \mathrm{~V} \mathrm{DC}$ voltage from the solar panel to $210 \mathrm{~V}$ AC voltage which can be used to run most of the electronic home appliances. By increasing the order of the solar panel, H-bridge and Battery, we can also run all the electronic home appliances which we use in our day to day life. By this we are making use of the renewable sources of energy that is solar energy to some extend to meet the electricity requirements.

\section{REFERENCES}

[1]. D Chauhan, S Agarwal, Suman M.K,"PoliciesFor Development Of Photovoltaic Technology:A Review" International Journal of software \& hardware research in engineering, Vol. 1, pp. 52-57, December 2013.

[2]. A Mamun A, M Elahi, M Quamruzzaman ,MTomal, "Design and Implementation of Single Phase Inverter" International Journal of Science and Research (IJSR), Vol.2, P 163-167, february 2013.

[3]. A Qazalbash, A Amin, A Manan, M Khalid, "design and implementation ofmicrocontroller based PWM technique forsine wave inverter" International Conference on power Engineering Energy and Electrical Drives, , P 163-167, March 2009, IEEE.

[4]. L Hassaine, E Olías, M Haddadi, A Malek, " Asymmetric SPWM used in inverter grid connected" Revue des Energies Renouvelables Vol. 10, pp. 421429,2007.

[5]. M.N Isa, M.I Ahmad, A.Z Murad, M.K Arshad, "FPGA Based SPWM Bridge Inverter ", American Journal of Applied

[6]. B Ismil, S Taib, A Saad, M Isa, " development of control circuit for single phase inverter using atmelmicrocontroller" First InternationalConference PEC, p 437-440, November 2006,IEEE.

[7]. S.M Islam, G.M sharif, "microcontroller based sinusoidal PWM inverter for photovoltaic application" First InternationalConference development in renewable energy technology, p 1-4, December 2009, IEEE.

[8]. P Zope, P Bhangale, P Sonare, S Suralkar,"design and implementation of carrier based sinusoidal PWM inverter" International Journal of advanced research in electrical, electronics and instrumentation engineering, Vol 1, pp.230-236, October 2012.

[9]. R Senthilkumar, M Singaaravelu, " designof single phase inverter usingdsPIC30F4013" International JournalEngineering Research \& Technology (IJERT), Vol 2, pp. 6500-6506, 2012.

[10].B Ismail, STaib, M Isa, I Daut, A.M saad, F Fauzy, " MicrocontrollerImplementation of single phase inverter switching strategies" International Conference on Control, Instrumentationand Mechatronics Engineering, p 104-107,May 2007.

[11].Mohamed A.Ghalib1, Yasser S.Abdalla 2, R. M.Mostafa31 "Design and Implementation of a Pure Sine Wave Single Phase Inverter for Photovoltaic Applications". Automatic Control Department, Faculty of Industrial Education, Beni-suef University, Egypt 